\title{
Technical note: Coupling infrared gas analysis and cavity ring down spectroscopy for autonomous, high-temporal-resolution measurements of DIC and $\delta^{13} \mathrm{C}-\mathrm{DIC}$
}

\author{
Mitchell Call $^{1,3}$, Kai G. Schulz ${ }^{2}$, Matheus C. Carvalho ${ }^{2}$, Isaac R. Santos ${ }^{3}$, and Damien T. Maher ${ }^{1,3}$ \\ ${ }^{1}$ School of Environment, Science and Engineering, Southern Cross University, Lismore, NSW, 2480, Australia \\ ${ }^{2}$ Centre for Coastal Biogeochemistry, School of Environment, Science and Engineering, Southern Cross University, \\ Lismore, NSW, 2480, Australia \\ ${ }^{3}$ National Marine Science Centre, School of Environment, Science and Engineering, Southern Cross University, \\ Coffs Harbour, NSW, 2450, Australia
}

Correspondence to: Mitchell Call (m.call.10@ student.scu.edu.au)

Received: 21 November 2016 - Discussion started: 22 November 2016

Revised: 8 February 2017 - Accepted: 13 February 2017 - Published: 15 March 2017

\begin{abstract}
A new approach to autonomously determine concentrations of dissolved inorganic carbon (DIC) and its carbon stable isotope ratio $\left(\delta^{13} \mathrm{C}-\mathrm{DIC}\right)$ at high temporal resolution is presented. The simple method requires no customised design. Instead it uses two commercially available instruments currently used in aquatic carbon research. An inorganic carbon analyser utilising non-dispersive infrared detection (NDIR) is coupled to a Cavity Ring-down Spectrometer (CRDS) to determine DIC and $\delta^{13} \mathrm{C}$-DIC based on the liberated $\mathrm{CO}_{2}$ from acidified aliquots of water. Using a small sample volume of $2 \mathrm{~mL}$, the precision and accuracy of the new method was comparable to standard isotope ratio mass spectrometry (IRMS) methods. The system achieved a sampling resolution of $16 \mathrm{~min}$, with a DIC precision of \pm 1.5 to $2 \mu \mathrm{mol} \mathrm{kg}{ }^{-1}$ and $\delta^{13} \mathrm{C}$-DIC precision of $\pm 0.14 \%$ o for concentrations spanning 1000 to $3600 \mu \mathrm{mol} \mathrm{kg}{ }^{-1}$. Accuracy of $0.1 \pm 0.06 \%$ for $\delta^{13} \mathrm{C}$-DIC based on DIC concentrations ranging from 2000 to $2230 \mu \mathrm{mol} \mathrm{kg}{ }^{-1}$ was achieved during a laboratory-based algal bloom experiment. The high precision data that can be autonomously obtained by the system should enable complex carbonate system questions to be explored in aquatic sciences using high-temporal-resolution observations.
\end{abstract}

\section{Introduction}

Dissolved inorganic carbon (DIC) is an important component of the evolving global carbon cycle, with $\sim 26 \%$ of yearly anthropogenic carbon dioxide $\left(\mathrm{CO}_{2}\right)$ emissions stored as DIC in the global ocean (Le Quéré et al., 2015). This influx of carbon to the oceans has resulted in increased fieldmonitoring (Sabine et al., 2010), laboratory-based experiments of how changing seawater carbonate chemistry affects biological processes (Gattuso and Hansson, 2011), and the development of new measurement technologies (Byrne, 2014; Martz et al., 2015). Currently, the spatial and temporal coverage of paired DIC and carbon stable isotope ratio $\left(\delta^{13} \mathrm{C}-\mathrm{DIC}\right)$ measurements is poor (Becker et al., 2016). However, greater interest is being placed on the coupled high-resolution measurement of DIC and $\delta^{13} \mathrm{C}-$ DIC as it can provide insights into the processes controlling DIC concentrations, helping elucidate flows of carbon within and between reservoirs (Bass et al., 2014b).

Whilst a variety of methods to autonomously measure DIC concentrations have been developed (Bandstra et al., 2006; Fassbender et al., 2015; Huang et al., 2015; Liu et al., 2013), the conventional method for determining $\delta^{13} \mathrm{C}$-DIC requires discrete samples to be collected and stored prior to acidification and analysis in a laboratory by isotope ratio mass spectrometry (IRMS). IRMS analysis offers high precision; however, the collection, handling and preservation of discrete samples may introduce sampling artefacts and reduce accu- 
racy (Li and Liu, 2011; Taipale and Sonninen, 2009). Furthermore, the laborious process limits sampling frequency, often restricting temporal and spatial coverage of coupled DIC and $\delta^{13} \mathrm{C}-\mathrm{DIC}$ measurements.

High-resolution, field-based measurement of $\mathrm{CO}_{2}$ and its carbon stable isotope value $\left({ }^{13} \mathrm{C}-\mathrm{CO}_{2}\right)$ is now achievable via laser spectroscopy systems such as Cavity RingDown Spectrometers (CRDSs) (Crosson, 2008) and Off-Axis Integrated Cavity Output Spectroscopy (OA-ICOS) (Baer et al., 2002), with precision and accuracy comparable to laboratory-based IRMS (Vogel et al., 2013; Berryman et al., 2011; Midwood and Millard, 2011). The use of CRDSs in the aquatic environment is becoming more prevalent with CRDSs successfully coupled to air-water equilibrators for on-site, high-resolution measurement of dissolved $\mathrm{CO}_{2}$ and its isotopic composition (Maher et al., 2013b; Becker et al., 2012). Recently, Bass et al. (2012) coupled a CRDS to a customised acidification interface utilising expanded polytetrafluoroethylene (ePTFE) tubing to measure in situ concentrations of DIC and its $\delta^{13} \mathrm{C}-\mathrm{DIC}$. The permeablemembrane-based equilibration system autonomously measured DIC and $\delta^{13} \mathrm{C}$-DIC at 15 min intervals to a precision of $\pm 10 \mu \mathrm{mol} \mathrm{kg}^{-1}$ and $\pm 0.2 \%$ respectively, and has been shown to be sufficient for identifying spatial and short-term temporal variability in DIC concentrations in a variety of aquatic systems (Bass et al., 2013, 2014a, b). However, a precision of $\sim 2 \mu \mathrm{mol} \mathrm{kg}-1$ or better is required in order to assess other processes such as long-term anthropogenically induced changes to oceanic carbon chemistry (Newton et al., 2014) or in laboratory-based experiments when trying to detect small changes in DIC.

This paper presents an alternative approach to autonomously determine concentrations of DIC and $\delta^{13} \mathrm{C}-\mathrm{DIC}$. The simple method does not require the need to design or replicate a customised system. Instead, it couples two commercially available instruments, an inorganic carbon analyser utilising non-dispersive infrared detection (NDIR) and a CRDS. The system can be automated, is low maintenance, and achieves a sampling resolution of $\sim 16 \mathrm{~min}$. Using only a small sample volume $(2 \mathrm{~mL})$, the method achieves high precision and accuracy comparable to traditional IRMS techniques.

\section{Materials and procedures}

\subsection{Approach}

Two commercially available instruments, an Autonomous Infra Red Inorganic Carbon Analyser (AIRICA, Marianda Company, Kiel, Germany) and a CRDS (Picarro G2201-i, Picarro Inc., Santa Clara, CA, USA), were coupled in order to autonomously measure concentrations of DIC and its $\delta^{13} \mathrm{C}$-DIC ratio based on the $\mathrm{CO}_{2}$ extracted from acidified samples (Fig. 1). These instruments offer high precision and

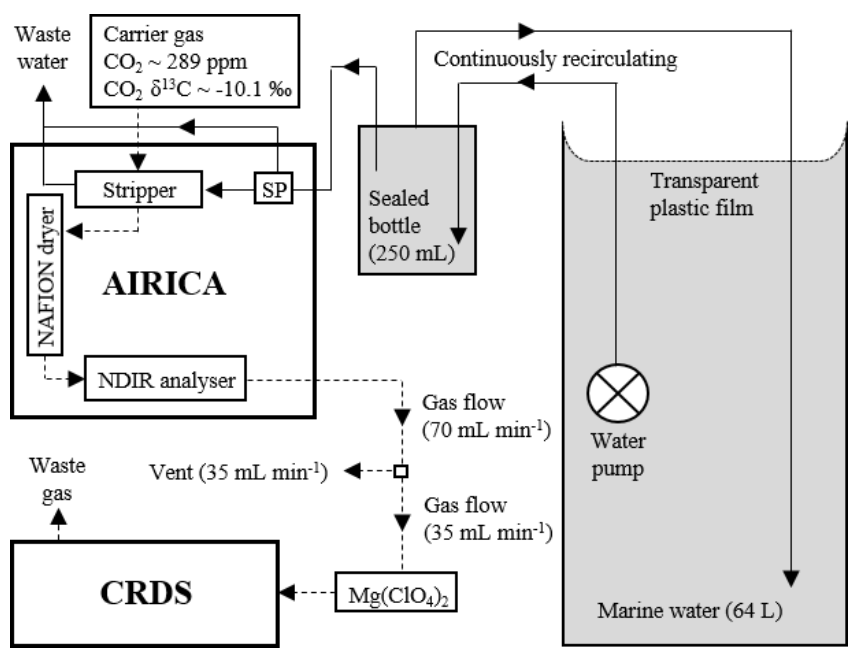

Figure 1. Schematic of the coupled Autonomous Infra Red Inorganic Carbon Analyser (AIRICA) and Cavity Ring Down Spectrometer (CRDS) set up to autonomously and continuously measure DIC concentrations and $\delta{ }^{13} \mathrm{C}$-DIC values. Solid arrows indicate liquid flow and dashed arrows indicate gas flow. $\mathrm{SP}=$ syringe pump.

accuracy, and are currently used in aquatic carbon research. To test the response of the method, here-in termed AIRICACRDS, laboratory-based experiments on precision were conducted as well as a mesocosm experiment simulating an algal bloom in coastal waters.

\subsection{Instrumentation}

The AIRICA system determines DIC to within \pm 1.5 to $2 \mu \mathrm{mol} \mathrm{kg}-1(0.1 \%)$ based on the NDIR gas analysis method (Goyet and Snover, 1993; O'Sullivan and Millero, 1998). Briefly, the AIRICA's high precision syringe pump draws a sample into a stripper that is pre-loaded with acid, effectively reducing the sample $\mathrm{pH}$ below 4.5 and converting all DIC to $\mathrm{CO}_{2}$. A carrier gas strips the $\mathrm{CO}_{2}$ from the acidified sample and the gas stream flows through a Peltier-element cooled condenser, followed by a Nafion dryer (both reducing water vapour content) before measurement by a NDIR analyser (LI-COR LI-7000, LI-COR Inc., Lincoln, NE, USA). DIC concentrations are determined by integrating the $\mathrm{CO}_{2}$ mixing ratio signal in the NDIR analyser over the integration period, with the area versus concentration relationship established by 5-point calibration using in-house standards. The calibration factor was validated against Dickson certified reference materials (CRMs; Batch \# 136, DIC $2021.15 \mu \mathrm{mol} \mathrm{kg}^{-1}$, Salinity 33.678 ). The carrier gas used comprised of instrument air (as opposed to $\mathrm{CO}_{2}$-free carrier gas), with a background $\mathrm{CO}_{2}$ mixing ratio of $289 \mathrm{ppm}$ and a $\delta^{13} \mathrm{C}-\mathrm{CO}_{2}$ of $-10.1 \%$. This carrier gas was used as the CRDS requires a gas with a similar composition to air. Furthermore, as the lower specified concentration range of the CRDS is $\sim 380 \mathrm{ppm}$, to achieve the precision and accuracy obtained by the AIRICA-CRDS 
from the $\mathrm{CO}_{2}$ extracted from a small sample $(2 \mathrm{~mL})$, the background $\mathrm{CO}_{2}$ enables accurate measurement of a $\delta^{13} \mathrm{C}-$ $\mathrm{CO}_{2}$ over a greater proportion of the integration period (discussed below).

The CRDS uses a laser-based spectroscopic technique that measures the individual carbon isotopologues $\left({ }^{12} \mathrm{C}\right.$ and $\left.{ }^{13} \mathrm{C}\right)$ of $\mathrm{CO}_{2}$ at $\sim 1 \mathrm{~Hz}$ and converts to standard $\delta^{13} \mathrm{C}(\%$ ) notation (referenced to Vienna PeeDee Belemnite). When the instrument is set in the $\mathrm{CO}_{2}$-isotope-only operating mode as used in this experiment (the CRDS can also simultaneously determine the carbon stable isotope ratio of methane), the guaranteed precision of the instrument by the manufacturer is $0.05 \%$ for the $\mathrm{CO}_{2}$ concentration (ppm) and $0.12 \%$ for $\delta^{13} \mathrm{C}\left(1 \sigma, 5 \mathrm{~min}\right.$ average) spanning 380 to $2000 \mathrm{ppm} . \delta^{13} \mathrm{C}-$ DIC was determined using the $\delta^{13} \mathrm{C}$ values of the extracted $\mathrm{CO}_{2}$ measured during the integration period (see Sect. 2.4).

The coupling of the two instruments was achieved by simply linking the outlet of the AIRICA's NDIR analyser with the inlet of the CRDS using polyethylene lined Bev-A-Line ${ }^{\circledR}$ IV (1/8" ID, $1 / 4^{\prime \prime}$ OD) tubing (Fig. 1). A vent ensured no pressure build-up at the inlet of the CRDS or back pressure on the AIRICA as the gas flow rate for the AIRICA varied from 70 to $300 \mathrm{~mL} \mathrm{~min}^{-1}$ (discussed below), while the CRDS has a flow rate of $\sim 35 \mathrm{~mL} \mathrm{~min}^{-1}$. An additional drying agent (magnesium perchlorate) was used to dry the gas stream prior to entering the CRDS to minimise any potential artefacts in isotope values introduced by uncertainties in the manufacturers' in-built water-vapour corrections (Nara et al., 2012). Magnesium perchlorate was used as it does not induce a delay in $\mathrm{CO}_{2}$ response time as is the case with some other desiccants (e.g. Drierite) (Webb et al., 2016).

To maximise precision and accuracy, DIC and $\delta^{13} \mathrm{C}-\mathrm{DIC}$ were determined from separate injections. The measurement parameters were customised for each analysis such that the integration period for DIC and $\delta^{13} \mathrm{C}$-DIC were 100 and $310 \mathrm{~s}$ respectively. Therefore, in order to achieve autonomous measurement of DIC and $\delta^{13} \mathrm{C}$-DIC, a computer script using AutoIt (Carvalho, 2017) was developed to autonomously modify the AIRICA's operating parameters at pre-determined time intervals without the need for an operator (the computer script is supplied as Supplement). The script was sequenced so that a single measurement cycle consisted of the AIRICA system acidifying three aliquots of sample. The first aliquot was used to flush the system, the second aliquot was to determine DIC concentration, and the third aliquot was to determine $\delta^{13} \mathrm{C}$-DIC. The system was flushed with carrier gas between each aliquot to remove the excess $\mathrm{CO}_{2}$ and return to carrier gas concentrations. The cycle was then repeated, achieving a DIC and $\delta^{13} \mathrm{C}$-DIC measurement, on average, every $\sim 16 \mathrm{~min}$ (refer to Supplement Fig. S1 for a depiction of the typical CRDS output for a single measurement cycle).

\subsection{Procedure}

To determine DIC, the AIRICA's syringe pump was rinsed twice with $2100 \mu \mathrm{L}$ of sample (filled and emptied at $300 \mu \mathrm{L} \mathrm{s}^{-1}$ ), with the first rinse going directly to waste and the second rinse wasted via the stripper (Fig. 1). The syringe pump then drew $2000 \mu \mathrm{L}$ of sample at $200 \mu \mathrm{L} \mathrm{s}^{-1}$ which was then injected at $80 \mu \mathrm{L} \mathrm{s}^{-1}$ into the stripper, to which two drops of $10 \% \mathrm{H}_{3} \mathrm{PO}_{4}$ had been added. With a carrier gas flow rate through the stripper set a $300 \mathrm{~mL} \mathrm{~min}^{-1}$, DIC concentrations were determined from integrating the $\mathrm{CO}_{2}$ mixing ratio signal in the LI-COR during an integration period of $100 \mathrm{~s}$. The system was then flushed with carrier gas at $150 \mathrm{~mL} \mathrm{~min}^{-1}$ to purge the liberated $\mathrm{CO}_{2}$ from the system and return to carrier gas values prior to $\delta^{13} \mathrm{C}-\mathrm{DIC}$ sampling. Sampling volume for $\delta^{13} \mathrm{C}$-DIC was the same as for DIC; however, to obtain a longer integration period the following AIRICA parameters were adjusted: the rate the sample was injected from the syringe pump to the stripper (i.e. injection rate) was reduced to $15 \mu \mathrm{L} \mathrm{s}^{-1}$ (from $80 \mu \mathrm{L} \mathrm{s}^{-1}$ ), the carrier gas flow rate through the stripper was reduced to $70 \mathrm{~mL} \mathrm{~min}^{-1}$ (from $300 \mathrm{~mL} \mathrm{~min}^{-1}$ ), and the integration period was increased to $310 \mathrm{~s}$ (from $100 \mathrm{~s}$ ). $\delta^{13} \mathrm{C}-\mathrm{DIC}$ was determined from the $\delta^{13} \mathrm{C}-\mathrm{CO}_{2}$ data measured at $\sim 1 \mathrm{~Hz}$ during the integration period (discussed below). After the sampling for $\delta^{13} \mathrm{C}$-DIC was completed, the cycle was restarted autonomously using the custom AutoIt script.

\subsection{Determination of $\delta^{13} \mathrm{C}$-DIC}

The $\delta^{13} \mathrm{C}-\mathrm{CO}_{2}$ of the gas stream is a function of the carrier gas and that of the liberated $\mathrm{CO}_{2}$ from the acidified sample (Eq. 1):

$$
\begin{aligned}
\delta^{13} \mathrm{C}_{\text {total }} & =\left(\delta^{13} \mathrm{C}_{\text {carrier }} \times f \mathrm{CO}_{2 \text { carrier }}\right) \\
& +\left(\delta^{13} \mathrm{C}_{\text {sample }} \times f \mathrm{CO}_{2 \text { sample }}\right),
\end{aligned}
$$

whereby

$$
\begin{aligned}
& f \mathrm{CO}_{2 \text { carrier }}=\mathrm{CO}_{2 \text { carrier }} / \mathrm{CO}_{2 \text { total }} \\
& f \mathrm{CO}_{2 \text { sample }}=\mathrm{CO}_{2 \text { sample }} / \mathrm{CO}_{2 \text { total }} \\
& \mathrm{CO}_{2 \text { sample }}=\mathrm{CO}_{2 \text { total }}-\mathrm{CO}_{2 \text { carrier}},
\end{aligned}
$$

where $\delta^{13} \mathrm{C}_{\text {total }}$ is the $\delta^{13} \mathrm{C}-\mathrm{CO}_{2}$ of the measured gas stream $\mathrm{CO}_{2}(\% \circ), \delta^{13} \mathrm{C}_{\text {carrier }}$ is the $\delta^{13} \mathrm{C}-\mathrm{CO}_{2}$ of the carrier gas $\mathrm{CO}_{2}$ $(\%), \mathrm{CO}_{2}$ carrier is the ${ }^{12+13} \mathrm{CO}_{2}$ concentration of the carrier gas (ppm), $\delta^{13} \mathrm{C}_{\text {sample }}$ is the $\delta^{13} \mathrm{C}-\mathrm{CO}_{2}$ of the acidified sample (\%o), $\mathrm{CO}_{2}$ sample is the ${ }^{12+13} \mathrm{CO}_{2}$ concentration of the acidified sample (ppm), and $\mathrm{CO}_{2}$ total is the ${ }^{12+13} \mathrm{CO}_{2}$ concentration of the measured gas stream (ppm).

The $\delta^{13} \mathrm{C}-\mathrm{CO}_{2}$ values of $\mathrm{CO}_{2}$ concentrations less than $400 \mathrm{ppm}$ were excluded due to the guaranteed specifications of the instrument spanning 380 to $2000 \mathrm{ppm}$. Of the remaining $\delta^{13} \mathrm{C}-\mathrm{CO}_{2}$ values, a mass balance was then used (to account for the $\delta^{13} \mathrm{C}$ value of the carrier gas) to determine a 
sample $\delta^{13} \mathrm{C}-\mathrm{CO}_{2}$ (i.e. $\delta^{13} \mathrm{C}_{\text {sample }}$ ) value based on each measured $\mathrm{CO}_{2}$ concentration (Eq. 2):

$$
\begin{aligned}
\delta^{13} \mathrm{C}_{\text {sample }} & =\left[\left(\delta^{13} \mathrm{C}_{\text {total }} \times \mathrm{CO}_{2 \text { total }}\right)\right. \\
& \left.-\left(\delta^{13} \mathrm{C}_{\text {carrier }} \times \mathrm{CO}_{2 \text { carrier }}\right)\right] / \\
& \left(\mathrm{CO}_{2 \text { total }}-\mathrm{CO}_{2 \text { carrier }}\right)
\end{aligned}
$$

Five iterations of outlier removal were conducted on the $\sim 1$ $\mathrm{Hz} \delta^{13} \mathrm{C}_{\text {sample values, with removal of values with an abso- }}$ lute difference (versus the mean of all $\delta^{13} \mathrm{C}_{\text {sample values for }}$ the sample) greater than two times the standard deviation of the sample. The remaining $\delta^{13} \mathrm{C}_{\text {sample values were then av- }}$ eraged to determine the final $\delta^{13} \mathrm{C}$-DIC value of the sample. All analysis was undertaken using Matlab (The Mathworks Inc., Natick, MA, USA) (see supplementary information for script).

\subsection{Evaluation of precision and accuracy}

$\delta^{13} \mathrm{C}$-DIC standards were made using $\mathrm{Na}_{2} \mathrm{CO}_{3}$ for the isotopically heavy standard $\left(-3.2 \pm 0.1 \%\right.$ ) and $\mathrm{K}_{2} \mathrm{CO}_{3}$ for the depleted standard $(-26.8 \pm 0.1 \%$ ), with both solids verified by IRMS using the international reference materials NBS-19 and LSVEC. The $\mathrm{Na}_{2} \mathrm{CO}_{3}$ solid was used to make a set of five standard solutions ranging from $\sim 500$ to $\sim 3600 \mu \mathrm{mol} \mathrm{kg}^{-1}$ and one standard solution was made using the $\mathrm{K}_{2} \mathrm{CO}_{3}$ solid $\left(\sim 2000 \mu \mathrm{mol} \mathrm{kg}{ }^{-1}\right)$. All standards were made by dissolving carbonate solids in ultra-pure water (18.2 Milli-Q $\left.{ }^{\circledR}\right)$. Precision was evaluated based on the standard deviation of at least six replicate measurements for each standard. Accuracy was tested by comparing AIRICACRDS $\delta{ }^{13} \mathrm{C}$-DIC values to IRMS-measured values from discrete samples collected during the bloom experiment (below). Both the precision measurements and bloom experiments were undertaken in a temperature-controlled laboratory with temperature varying by $<2{ }^{\circ} \mathrm{C}$ over the course of the experiments.

\subsection{Algal bloom experiment}

An algal bloom experiment was conducted to test the response of the method (Fig. 1) over an $\sim 8$-day period. Seawater (salinity 35.690) was collected from a nearby beach $\left(28^{\circ} 49^{\prime} 22.01^{\prime \prime} \mathrm{S}, 153^{\circ} 36^{\prime} 23.48^{\prime \prime} \mathrm{E}\right)$ the morning the experiment commenced (9 January 2016). The water was enriched with $64 \mu \mathrm{mol} \mathrm{L}{ }^{-1}$ each of nitrate $\left(\mathrm{NO}_{3}^{-}\right)$and orthosilicate $\left(\mathrm{SiO}_{4}^{4-}\right)$, and $4 \mu \mathrm{mol} \mathrm{L}{ }^{-1}$ of orthophosphate $\left(\mathrm{PO}_{4}^{3-}\right)$. In order to counteract the impact of the $\mathrm{SiO}_{4}^{4-}$ addition on total alkalinity, $128 \mu \mathrm{mol} \mathrm{L}{ }^{-1}$ of hydrochloric acid $(\mathrm{HCl})$ was added. The mesocosm was incubated under high-pressure sodium bulbs (400W Phillips Son T Agro) at $\sim 200 \mu \mathrm{mol} \mathrm{m}^{-2} \mathrm{~s}^{-1}$ for $18 \mathrm{~h}$ per day (12:00 local time (LT) to 06:00 LT). The surface of the incubation vessel was covered with a transparent sheet of plastic film to inhibit evaporation and $\mathrm{CO}_{2}$ exchange with the atmosphere, allowing for an interpretation of the results in terms of a closed system. Macroalgae (Ulva sp.) and an additional dose of nutrients were added to the sample water on the 25 January 2016 (10:00 LT) to further enhance biological activity. To achieve unattended sampling, incubated water was continuously recirculated through a sealed Schott bottle $(250 \mathrm{~mL})$ at $\sim 1 \mathrm{~L} \mathrm{~min}^{-1}$, from where the AIRICA's high-precision syringe pump drew the sample (Fig. 1). DIC and $\delta{ }^{13} \mathrm{C}$-DIC were sampled autonomously according to the procedure outlined above. In order to evaluate the accuracy of the AIRICA-CRDS method, 19 discrete samples for $\delta^{13} \mathrm{C}$-DIC were collected throughout the bloom experiment for IRMS analysis. The samples were generally collected at the start and end of the light period from the return line of the recirculating system into $40 \mathrm{~mL}$ precombusted borosilicate vials, closed without headspace by Teflon-lined septa screw caps, poisoned with $50 \mu \mathrm{L}$ of saturated $\mathrm{HgCl}_{2}$ solution and stored at $\sim 4{ }^{\circ} \mathrm{C}$ in the dark until analysis (within 1 week). The samples were also analysed for $\delta^{13} \mathrm{C}$-DOC to determine the isotopic composition of the carbon pool available for microbial respiration. Samples were analysed using an OI Aurora 1030W TOC analyser interfaced to a Thermo Delta $V^{\text {Plus }}$ Isotope Ratio Mass Spectrometer (Maher and Eyre, 2011). Precision of $\delta^{13} \mathrm{C}-\mathrm{DIC}$ and $\delta{ }^{13} \mathrm{C}$-DOC IRMS measurements were $\pm 0.1 \%$ and $\pm 0.3 \%$ o respectively. Samples for DOC concentration were analysed using a Shimadzu (TOC-VCPH) analyser. Particulate organic carbon (POC, mostly representing phytoplankton) was sampled at the end of the experiment by filtering $150 \mathrm{~mL}$ of the incubated water through pre-combusted Whatman (GF/F) filters and dried $\left(60^{\circ} \mathrm{C}\right)$ before analysis. Macroalgae was sampled at the end of the experiment, dried $\left(60^{\circ} \mathrm{C}\right)$ and ground prior to analysis. The $\delta^{13} \mathrm{C}$ values of the macroalgae and the POC were measured in triplicate samples using a Thermo Flash elemental analyser coupled to a Delta $V^{\text {plus }}$ IRMS $\left( \pm 0.1 \%\right.$ ). All $\delta^{13} \mathrm{C}$ values are reported based on the VPDB scale.

\section{Results and discussion}

\subsection{Precision}

The AIRICA-CRDS system exhibited a relatively small but detectable concentration effect on measured $\delta^{13} \mathrm{C}$-DIC with an increase of $0.19 \%$ observed from $1000 \mu \mathrm{mol} \mathrm{kg}^{-1}$ to $3600 \mu \mathrm{mol} \mathrm{kg}^{-1}$ (Fig. 2a). It is unclear if this effect is an artefact of the system or if it can be explained by in-gassing of isotopically lighter atmospheric $\mathrm{CO}_{2}$ (due to the high total alkalinity to DIC ratio of the standards) during the making of standards. $\mathrm{CO}_{2}$ in-gassing would have a larger effect on lower concentration standards (making them more depleted) than higher concentration standards, which follows the pattern observed here (Fig. 2a). Similarly, Bass et al. (2012) reported a concentration effect of $<0.2 \%$ increase from 1000 


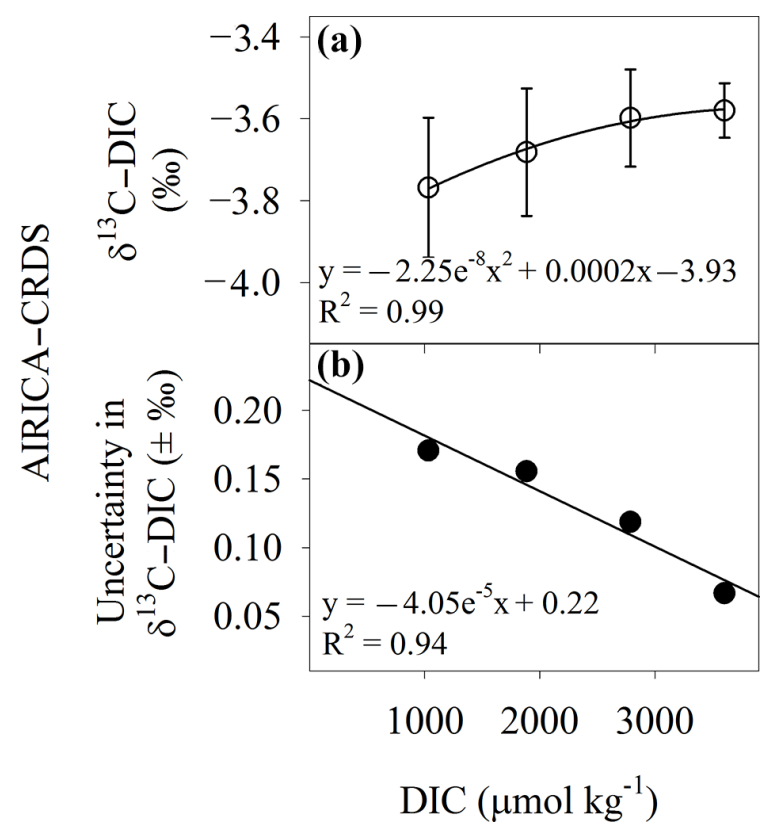

Figure 2. (a) Concentration effect on $\delta^{13} \mathrm{C}$-DIC data produced by the AIRICA-CRDS. (b) Uncertainty in $\delta^{13} \mathrm{C}$-DIC versus DIC concentration.

to $2100 \mu \mathrm{mol} \mathrm{kg} \mathrm{kg}^{-1}$ and did not correct $\delta^{13} \mathrm{C}$-DIC values as the observed effect was within the precision of internal calibration standards.

The AIRICA-CRDS method had decreasing $\delta^{13} \mathrm{C}-\mathrm{DIC}$ uncertainty with higher DIC concentrations (Fig. 2b). Standard deviations of the isotopically heavy standards decreased from $\pm 0.17 \%$ at $\sim 1000 \mu \mathrm{mol} \mathrm{kg} \mathrm{k}^{-1}(n=6)$ to $\pm 0.07 \%$ at $\sim 3600 \mu \mathrm{mol} \mathrm{kg}{ }^{-1} \quad(n=8)$; however, below $1000 \mu \mathrm{mol} \mathrm{kg}^{-1}$ standard deviations were relatively high $\left( \pm 0.63 \%\right.$ at $\left.500 \mu \mathrm{mol} \mathrm{kg}{ }^{-1}, n=6\right)$. For the isotopically lighter standard, the uncertainty was $\pm 0.17 \%$ at a DIC concentration of $\sim 2000 \mu \mathrm{mol} \mathrm{kg}{ }^{-1}$ (Supplement Table S1). Bass et al. (2012) also reported decreasing uncertainty with increasing concentrations of DIC. Their membrane-based equilibration system attained standard deviations $< \pm 0.2 \%$ o for concentrations above $360 \mu \mathrm{mol} \mathrm{kg}{ }^{-1}$ using a sample volume of $350 \mathrm{~mL}$ and an equilibration time of $720 \mathrm{~s}$. In comparison, AIRICA-CRDS achieved $< \pm 0.2 \%$ uncertainty at $\sim 1000 \mu \mathrm{mol} \mathrm{kg}^{-1}$ on a sample volume of $2 \mathrm{~mL}$ and an integration time of $310 \mathrm{~s}$.

To achieve the manufacturer-guaranteed specifications of $\pm 0.12 \%$ o $\delta^{13} \mathrm{C}-\mathrm{CO}_{2}, \mathrm{CO}_{2}$ concentrations in the gas stream, which is a sum of the $\mathrm{CO}_{2}$ in the carrier gas and the liberated $\mathrm{CO}_{2}$ from the acidified sample, should be between 380 and $2000 \mathrm{ppm}$. The concentration of the liberated $\mathrm{CO}_{2}$ is a function of the sample size, the injection rate, and the gas flow rate, each of which can be independently adjusted by the user through the AIRICA software. For $\delta^{13} \mathrm{C}$-DIC measurements, the $2 \mathrm{~mL}$ of sample was injected into the stripper at $15 \mu \mathrm{L} \mathrm{s}^{-1}$ and extracted with a carrier gas flow rate

\section{AIRICA-CRDS \\ $\delta^{13} \mathrm{C}-\mathrm{DIC}(\%)$}

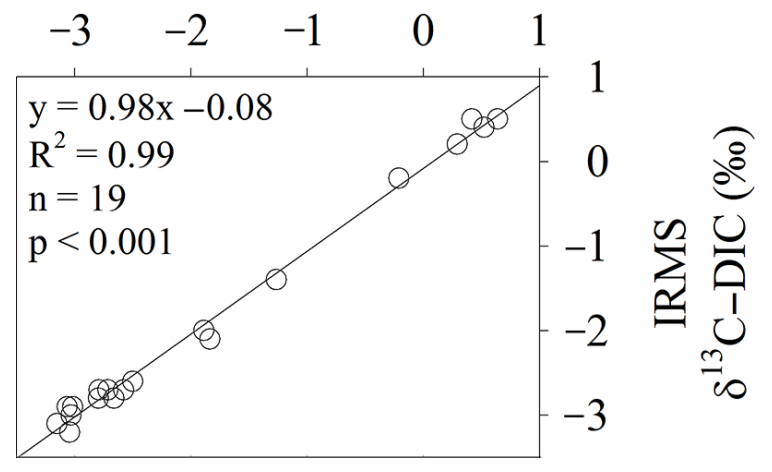

Figure 3. Comparison of AIRICA-CRDS $\delta^{13} \mathrm{C}$-DIC versus IRMS $\delta^{13} \mathrm{C}$-DIC.

of $70 \mathrm{~mL} \min ^{-1}$ (achieving a total measurement time of $310 \mathrm{~s}$ ), resulting in the AIRICA-CRDS achieving an average precision of $0.14 \pm 0.04 \%$ ( $n=84)$ for all standards above $1000 \mu \mathrm{mol} \mathrm{kg}{ }^{-1}$. While we optimised the system for coastal and oceanic DIC concentrations, if sampling low-DIC concentrations (i.e. $<1000 \mu \mathrm{mol} \mathrm{kg}{ }^{-1}$ ), similarly precise $\delta^{13} \mathrm{C}-$ DIC values may be achievable if, for example, a larger syringe volume is used to increase sample size. This ability for customisation adds to the functionality of the AIRICACRDS system. In comparison to the AIRICA-CRDS reported here, a worldwide proficiency test of $\delta^{13} \mathrm{C}$-DIC analysis found laboratory precision ranged from 0.1 to $0.5 \%$ o depending on different methodologies (Van Geldern et al., 2013). However, the inter-laboratory results revealed average standard deviations of \pm 0.45 and $\pm 0.47 \%$ o for $\delta^{13} \mathrm{C}$ DIC values for lake water and seawater measurements respectively.

\subsection{Accuracy}

Accuracy of the AIRICA-CRDS $\delta^{13} \mathrm{C}-\mathrm{DIC}$ was determined by direct comparison with IRMS measurements collected simultaneously during the algal bloom experiment (Fig. 3). The average difference in measured $\delta^{13} \mathrm{C}$ values between methods was $0.1 \pm 0.06 \%$, which is similar to the accuracy of the IRMS $(0.1 \%$ ). This robust relationship was based on DIC concentrations ranging from 1986 to $2232 \mu \mathrm{mol} \mathrm{kg}^{-1}$ (average $2129 \mu \mathrm{mol} \mathrm{kg}^{-1}$ ) during the dynamic bloom experiment. This demonstrates that the automated AIRICA-CRDS system described here attains similar accuracy to IRMS $\delta^{13} \mathrm{C}-\mathrm{DIC}$ measurements at typical coastal and oceanic DIC concentrations.

\subsection{Bloom experiment}

The performance of the AIRICA-CRDS to characterise changes in $\delta^{13} \mathrm{C}$-DIC values and DIC concentrations in the 


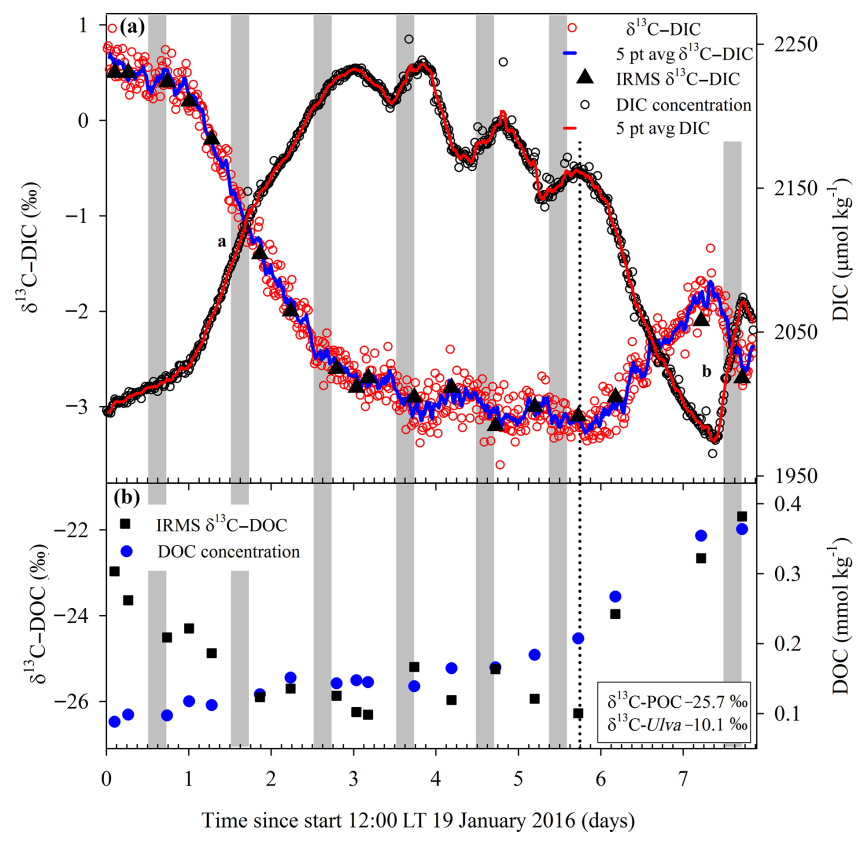

Figure 4. (a) $\delta^{13} \mathrm{C}$-DIC values and DIC concentrations measured by the AIRICA-CRDS system during the $\sim 8$-day laboratory bloom experiment. Blue and red lines are 5 -point averages for $\delta^{13} \mathrm{C}$-DIC and DIC respectively. Black triangles are discrete IRMS $\delta^{13} \mathrm{C}$-DIC values plotted for comparison. Shaded areas indicate dark incubations. Lower-case letters indicate the sections used for Keeling plots (see Fig. S2). Dotted line shows when macroalgae (Ulva sp.) and additional nutrients were added. (b) IRMS $\delta^{13} \mathrm{C}$-DOC values and DOC concentrations for discrete samples. Inset box displays IRMS $\delta^{13} \mathrm{C}$ values for POC and Ulva sp.

marine environment is demonstrated by the algal bloom experiment (Fig. 4a). A total of 664 DIC concentrations and $661 \delta^{13} \mathrm{C}$-DIC values were autonomously measured during the $\sim 8$-day incubation. Concentrations of DIC ranged from 1965 to $2253 \mu \mathrm{mol} \mathrm{kg}{ }^{-1}$ and $\delta^{13} \mathrm{C}$-DIC ranged from 0.96 to $-3.61 \%$.

The AIRICA-CRDS method captured a temporally inverse relationship between $\delta^{13} \mathrm{C}-\mathrm{DIC}$ values and DIC concentrations throughout the algal bloom experiment. During the first 3 days, respiration was the dominant metabolic process releasing isotopically lighter DIC (originating from organic matter). Respiration increased the pool of DIC from $\sim 1995$ to $\sim 2230 \mu \mathrm{mol} \mathrm{kg}^{-1}$ and simultaneously lowered $\delta^{13} \mathrm{C}$-DIC from $\sim 0.7$ to $\sim-2.7 \%$. After 3 days, diel cycling (light-dark) of DIC and $\delta^{13} \mathrm{C}$-DIC commenced, likely due to the time lag associated with primary producer biomass increase after the initial addition of nutrients. During daylight hours, photosynthetic production preferentially consumed the isotopically lighter ${ }^{12} \mathrm{CO}_{2}$ component of the DIC pool, decreasing DIC concentrations and increasing $\delta^{13} \mathrm{C}$ DIC values. Conversely, during the dark hours, respiration increased DIC concentrations and decreased $\delta^{13} \mathrm{C}-\mathrm{DIC}$ values. Over the course of days 4,5 , and 6 , overall net production

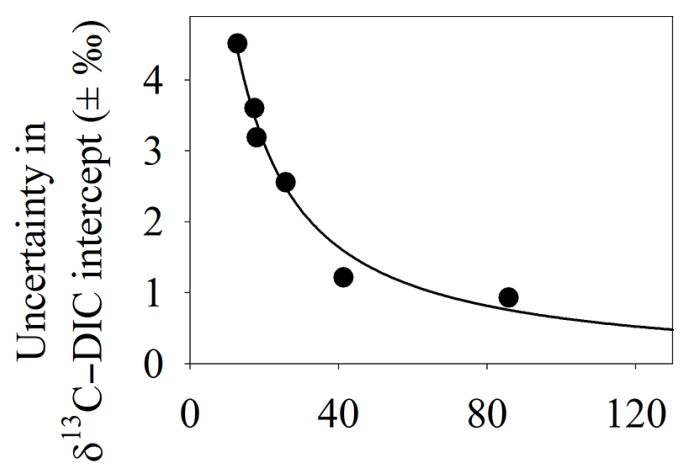

$\Delta$ DIC concentration $\left(\mu \mathrm{mol} \mathrm{kg}{ }^{-1}\right)$

Figure 5. Relationship between Keeling intercept uncertainty and changes in DIC concentration. Higher changes in DIC resulted in lower uncertainties in Keeling plot interpretations.

drew down the DIC pool. On day 7 no dark incubation occurred resulting in a large photosynthetically driven decrease in the DIC concentration from 2164 to $1965 \mu \mathrm{mol} \mathrm{kg}^{-1}$ and an increase of $\delta^{13} \mathrm{C}$-DIC from $\sim-3.1$ to $\sim-1.7 \%$. Similar diel variations were observed for DIC and $\delta^{13} \mathrm{C}-\mathrm{DIC}$ in a mesocosm coral reef metabolism experiment (Bass et al., 2012).

\subsection{Insights from high resolution DIC and $\delta^{13} \mathrm{C}$-DIC measurements}

The AIRICA-CRDS's high resolution measurements of $\delta^{13} \mathrm{C}-\mathrm{DIC}$ can provide insights into drivers of DIC in aquatic environments. To illustrate a potential application of the AIRICA-CRDS approach, Keeling plots are used to interpret carbon sources during a simulated algal bloom experiment. Keeling plots (Keeling, 1958) visualise a simple twocomponent mixing model and are commonly used to interpret sources of added carbon in aquatic, terrestrial, and atmospheric sciences (see Pataki et al., 2003 for details on underlying assumptions and types of regression models available). Using a Model II regression (which assumes errors in the measurement of both variables), the y-intercept of the regression between the inverse of DIC concentration (1/DIC) and $\delta^{13} \mathrm{C}$-DIC estimates the isotopic composition of the carbon source. The approach has been used to determine the isotopic composition of the DIC source in various settings including freshwater lakes (Karlsson et al., 2007), coral reefs (Carvalho et al., 2015), mangroves (Maher et al., 2013a), and groundwaters (Porowska, 2015).

The $\delta^{13} \mathrm{C}$-DIC source values were estimated by Keeling plots for each linear increase (respiration) in DIC concentrations during the simulated algal bloom based on 5-point averages of measured DIC and $\delta^{13} \mathrm{C}$-DIC (Fig. S2). The uncertainty in the intercept (i.e. the $\delta^{13} \mathrm{C}$-DIC source value) is dependent on the rate of change in DIC concentration during the dark incubation period (see Pataki et al., 2003 and 
references therein for regression formulations). Uncertainty decreased as the absolute change in DIC increased, achieving $<2 \%$ uncertainty when the change in DIC was greater than $\sim 40 \mu \mathrm{mol} \mathrm{kg}^{-1}$ (Fig. 5). It is noted that the intercept uncertainty is much higher than the uncertainty for each $\delta^{13} \mathrm{C}$-DIC and DIC value $\left( \pm 0.14 \%\right.$ and \pm 1.5 to $2 \mu \mathrm{mol} \mathrm{kg}^{-1}$ respectively). A Keeling plot, based on DIC concentrations during dark incubation periods over the first 3 days (Fig. S2a), produced a $\delta^{13} \mathrm{C}$-DIC intercept value of $-27.8 \pm 1.2 \%$, which is similar to that of terrestrial C3 vegetation (Smith and Epstein, 1971). In contrast, the $\delta^{13} \mathrm{C}-\mathrm{DIC}$ intercept value for the final dark incubation of $-17.4 \pm 0.9 \%$ (Fig. S2b) is similar to that of marine organic matter (OM). Thus, results suggest a distinct shift in the source of DIC during the course of the experiment, from terrestrially derived OM present in the sampled coastal seawater to marine-derived OM at the end. This is likely due to a shift towards a dominance of marine organic matter toward the end of the experiment as a result of the algal bloom and the added macroalgae (added on day 6 , Fig. 4).

The DOC results support our interpretation of a shift in the DIC source. DOC concentrations increased from $88 \mu \mathrm{mol} \mathrm{kg}{ }^{-1}$ at the beginning of the experiment to $364 \mu \mathrm{mol} \mathrm{kg}{ }^{-1}$ at the end. $\delta^{13} \mathrm{C}$-DOC values decreased during the first 3 days of the experiment before increasing during the final $\sim 2$ days. Keeling plot intercepts based on DOC concentrations for the initial $\sim 3$ day period $(-31.8 \pm 1.5 \%$ o $)$ and final $\sim 2$-day period $(-17.6 \pm 2 \%$ o $)$ suggest a distinct shift in the carbon source contributing to the DOC pool from a terrestrially derived DOC source to a marine source. This is consistent with the shift observed in the DIC pool. The IRMS $\delta^{13} \mathrm{C}-\mathrm{POC}$ results for phytoplankton $(-25.7 \%$ ) and macroalgae (i.e. Ulva sp., $-10.1 \%$ ) suggests a similar contribution of both sources to the final $\delta^{13} \mathrm{C}-\mathrm{DOC}$ intercept value of $-17.6 \%$ and the $\delta^{13} \mathrm{C}-\mathrm{DIC}$ value of $-17.4 \%$. The AIRICA-CRDS system could similarly be used to characterise the importance of various other processes, such as the relative importance of organic matter respiration versus carbonate dissolution as a source of DIC from coastal systems (Carvalho et al., 2015) and the importance of allochthonous versus autochthonous organic matter for supporting bacterial productivity (Guillemette et al., 2013).

\section{Comments}

The utility of the AIRICA-CRDS method for autonomous, high-resolution measurements of DIC and $\delta^{13} \mathrm{C}-\mathrm{DIC}$ in a laboratory configuration has been demonstrated. Yet, the simple system also has the capacity for field deployment. Both of the commercially available instruments (coupled without any modifications to their hardware) have been used in field-based studies. CRDSs have been deployed in a range of environmental settings including large research vessels (Bass et al., 2014b; Becker et al., 2012), vehicles (Maher et al., 2014), and small boats (Maher et al., 2015). Determination of DIC based on the NDIR gas analysis method has been used to conduct continuous shipboard measurements (Friederich et al., 2002; Hiscock and Millero, 2005), and the AIRICA system has been deployed on research vessels to determine concentrations of DIC from discrete samples (Balch et al., 2016; Bates et al., 2013, 2014). Assuming access to an appropriate power source and suitable environmental conditions to house the instruments, the AIRICA-CRDS system has potential to be deployed in the field; however, further testing is required to test this capability.

The AIRICA-CRDS is an alternative system that enables autonomous, high-resolution measurements of DIC and $\delta^{13} \mathrm{C}$-DIC with precision and accuracy comparable to traditional IRMS techniques. In the described configuration, the system achieved a sampling resolution of 16 mins, with a DIC precision of $\pm 1.5-2 \mu \mathrm{mol} \mathrm{kg}{ }^{-1}$ and $\delta^{13} \mathrm{C}$-DIC precision of $\pm 0.14 \%$ for concentrations spanning 1000 to $3600 \mu \mathrm{mol} \mathrm{kg}^{-1}$. A change in DIC concentrations of $\sim 40 \mu \mathrm{mol} \mathrm{kg}{ }^{-1}$ was sufficient to obtain a precision of $<2 \%$ o in source interpretations based on Keeling plots. Whilst we optimized the system for typical estuarine or marine DIC concentrations, the system has the potential to be optimised for other environments through changes to the syringe size, sample volume, and injection speed. This ability for customisation adds to the functionality of the AIRICA-CRDS system, offering the potential to explore complex carbonate system questions across a range of aquatic settings.

\section{Information about the Supplement}

The Supplement includes the AutoIt script, Matlab script, and Supplement figures and tables.

\section{The Supplement related to this article is available online at doi:10.5194/bg-14-1305-2017-supplement.}

Author contributions. Damien T. Maher, Kai G. Schulz, and Isaac R. Santos designed the study. Damien T. Maher, Kai G. Schulz, and Mitchell Call conducted the experiments. Matheus C. Carvalho developed the Autolt script and analysed all discrete samples. Kai G. Schulz developed the Matlab Scripts. Mitchell Call prepared the manuscript with contributions from all authors.

Competing interests. The authors declare that they have no conflict of interest.

Acknowledgements. We acknowledge funding from the Australian Research Council through grants DE140101733, DE150100581, and LE120100156. Kai G. Schulz is the recipient of an Australian Research Council Future Fellowship (FT120100384). 
Edited by: J. Middelburg

Reviewed by: N. Munksgaard and one anonymous referee

\section{References}

Baer, D. S., Paul, J. B., Gupta, M., and O'Keefe, A.: Sensitive absorption measurements in the near-infrared region using off-axis integrated-cavity-output spectroscopy, Appl. Phys. B, 75, 261265, doi:10.1007/s00340-002-0971-z, 2002.

Balch, W. M., Bates, N. R., Lam, P. J., Twining, B. S., Rosengard, S. Z., Bowler, B. C., Drapeau, D. T., Garley, R., Lubelczyk, L. C., Mitchell, C., and Rauschenberg, S.: Factors regulating the Great Calcite Belt in the Southern Ocean and its biogeochemical significance, Global Biogeochem. Cy., 30, 1124-1144, doi:10.1002/2016GB005414, 2016.

Bandstra, L., Hales, B., and Takahashi, T.: High-frequency measurements of total $\mathrm{CO}_{2}$ : Method development and first oceanographic observations, Mar. Chem., 100, 24-38, doi:10.1016/j.marchem.2005.10.009, 2006.

Bass, A. M., Bird, M. I., Munksgaard, N. C., and Wurster, C. M.: ISO-CADICA: Isotopic - continuous, automated dissolved inorganic carbon analyser, Rapid Commun. Mass Sp., 26, 639-644, doi:10.1002/rcm.6143, 2012.

Bass, A. M., O' Grady, D., Berkin, C., Leblanc, M., Tweed, S., Nelson, P. N., and Bird, M. I.: High diurnal variation in dissolved inorganic $\mathrm{C}, \delta^{13} \mathrm{C}$ values and surface efflux of $\mathrm{CO}_{2}$ in a seasonal tropical floodplain, Environ. Chem. Lett., 11, 399-405, doi:10.1007/s10311-013-0421-7, 2013.

Bass, A. M., Munksgaard, N. C., Leblanc, M., Tweed, S., and Bird, M. I.: Contrasting carbon export dynamics of human impacted and pristine tropical catchments in response to a short-lived discharge event, Hydrol. Proc., 28, 1835-1843, doi:10.1002/hyp.9716, 2014a.

Bass, A. M., Munksgaard, N. C., O’Grady, D., Williams, M. J. M., Bostock, H. C., Rintoul, S. R., and Bird, M. I.: Continuous shipboard measurements of oceanic $\delta^{18} \mathrm{O}, \delta \mathrm{D}$ and $\delta^{13} \mathrm{C}_{\mathrm{DIC}}$ along a transect from New Zealand to Antarctica using cavity ring-down isotope spectrometry, J. Mar. Syst., 137, 21-27, doi:10.1016/j.jmarsys.2014.04.003, 2014b.

Bates, N. R., Orchowska, M. I., Garley, R., and Mathis, J. T.: Summertime calcium carbonate undersaturation in shelf waters of the western Arctic Ocean: how biological processes exacerbate the impact of ocean acidification, Biogeosciences, 10, 5281-5309, doi:10.5194/bg-10-5281-2013, 2013.

Bates, N. R., Garley, R., Frey, K. E., Shake, K. L., and Mathis, J. T.: Sea-ice melt $\mathrm{CO}_{2}$-carbonate chemistry in the western Arctic Ocean: meltwater contributions to air-sea $\mathrm{CO}_{2}$ gas exchange, mixed-layer properties and rates of net community production under sea ice, Biogeosciences, 11, 6769-6789, doi:10.5194/bg11-6769-2014, 2014.

Becker, M., Andersen, N., Fiedler, B., Fietzek, P., Körtzinger, A., Steinhoff, T., and Friedrichs, G.: Using cavity ringdown spectroscopy for continuous monitoring of $\delta^{13} \mathrm{C}_{\left(\mathrm{CO}_{2}\right)}$ and $f \mathrm{CO}_{2}$ in the surface ocean, Limnol. Oceanogr.-Meth., 10, 752-766, doi:10.4319/lom.2012.10.752, 2012.

Becker, M., Andersen, N., Erlenkeuser, H., Humphreys, M. P., Tanhua, T., and Körtzinger, A.: An internally consistent dataset of $\delta^{13} \mathrm{C}$-DIC in the North Atlantic Ocean - NAC13v1, Earth Syst. Sci. Data, 8, 559-570, doi:10.5194/essd-8-559-2016, 2016.

Berryman, E. M., Marshall, J. D., Rahn, T., Cook, S. P., and Litvak, M.: Adaptation of continuous-flow cavity ring-down spectroscopy for batch analysis of $\delta^{13} \mathrm{C}$ of $\mathrm{CO}_{2}$ and comparison with isotope ratio mass spectrometry, Rapid Commun. Mass Sp., 25, 2355-2360, 2011.

Byrne, R. H.: Measuring Ocean Acidification: New Technology for a New Era of Ocean Chemistry, Environ. Sci. Technol., 48, 53525360, doi:10.1021/es405819p, 2014.

Carvalho, M. C., Santos, I. R., Maher, D. T., Cyronak, T., McMahon, A., Schulz, K. G., and Eyre, B. D.: Drivers of carbon isotopic fractionation in a coral reef lagoon: Predominance of demand over supply, Geochim. Cosmochim. Ac., 153, 105-115, doi:10.1016/j.gca.2015.01.012, 2015.

Carvalho, M. C.: Practical Laboratory Automation Made Easy with AutoIt, Wiley-VCH, Weinheim, 290 pp., 2017.

Crosson, E. R.: A cavity ring-down analyzer for measuring atmospheric levels of methane, carbon dioxide, and water vapor, Appl. Phys. B, 92, 403-408, doi:10.1007/s00340-008-3135-y, 2008.

Fassbender, A. J., Sabine, C. L., Lawrence-Slavas, N., De Carlo, E. H., Meinig, C., and Maenner Jones, S.: Robust Sensor for Extended Autonomous Measurements of Surface Ocean Dissolved Inorganic Carbon, Environ. Sci. Technol., 49, 3628-3635, doi:10.1021/es5047183, 2015.

Friederich, G. E., Walz, P. M., Burczynski, M. G., and Chavez, F. P.: Inorganic carbon in the central California upwelling system during the 1997-1999 El Niño-La Niña event, Prog. Oceanogr., 54, 185-203, doi:10.1016/S0079-6611(02)00049-6, 2002.

Fry, B. and Sherr, E. B.: $\delta^{13} \mathrm{C}$ Measurements as Indicators of Carbon Flow in Marine and Freshwater Ecosystems, in: Stable Isotopes in Ecological Research, edited by: Rundel, P. W., Ehleringer, J. R., and Nagy, K. A., Springer New York, New York, NY, 196-229, 1989.

Gattuso, J.-P. and Hansson, L.: Ocean acidification: background and history, in: Ocean Acidification, edited by: Hansson, L. and Gattuso, J.-P., Oxford University Press, 1-20, 2011.

Goyet, C. and Snover, A. K.: High-accuracy measurements of total dissolved inorganic carbon in the ocean: comparison of alternate detection methods, Mar. Chem., 44, 235-242, doi:10.1016/03044203(93)90205-3, 1993.

Guillemette, F., McCallister, S. L., and del Giorgio, P. A.: Differentiating the degradation dynamics of algal and terrestrial carbon within complex natural dissolved organic carbon in temperate lakes, J. Geophys. Res.-Biogeo., 118, 963-973, doi:10.1002/jgrg.20077, 2013.

Hiscock, W. T. and Millero, F. J.: Nutrient and carbon parameters during the Southern Ocean iron experiment (SOFeX), Deep-Sea Res. Pt. I, 52, 2086-2108, doi:10.1016/j.dsr.2005.06.010, 2005.

Huang, K., Cassar, N., Jonsson, B., Cai, W.-j., and Bender, M. L.: An Ultrahigh Precision, High-Frequency Dissolved Inorganic Carbon Analyzer Based on Dual Isotope Dilution and Cavity Ring-Down Spectroscopy, Environ. Sci. Technol., 49, 86028610, doi:10.1021/acs.est.5b01036, 2015.

Karlsson, J., Jansson, M., and Jonsson, A.: Respiration of allochthonous organic carbon in unproductive forest lakes determined by the Keeling plot method, Limnol. Oceanogr., 52, 603608, 2007. 
Keeling, C. D.: The concentration and isotopic abundances of atmospheric carbon dioxide in rural areas, Geochim. Cosmochim. Ac., 13, 322-334, doi:10.1016/0016-7037(58)90033-4, 1958.

Le Quéré, C., Moriarty, R., Andrew, R. M., Canadell, J. G., Sitch, S., Korsbakken, J. I., Friedlingstein, P., Peters, G. P., Andres, R. J., Boden, T. A., Houghton, R. A., House, J. I., Keeling, R. F., Tans, P., Arneth, A., Bakker, D. C. E., Barbero, L., Bopp, L., Chang, J., Chevallier, F., Chini, L. P., Ciais, P., Fader, M., Feely, R. A., Gkritzalis, T., Harris, I., Hauck, J., Ilyina, T., Jain, A. K., Kato, E., Kitidis, V., Klein Goldewijk, K., Koven, C., Landschützer, P., Lauvset, S. K., Lefèvre, N., Lenton, A., Lima, I. D., Metzl, N., Millero, F., Munro, D. R., Murata, A., S. Nabel, J. E. M., Nakaoka, S., Nojiri, Y., O’Brien, K., Olsen, A., Ono, T., Pérez, F. F., Pfeil, B., Pierrot, D., Poulter, B., Rehder, G., Rödenbeck, C., Saito, S., Schuster, U., Schwinger, J., Séférian, R., Steinhoff, T., Stocker, B. D., Sutton, A. J., Takahashi, T., Tilbrook, B., Van Der Laan-Luijkx, I. T., Van Der Werf, G. R., Van Heuven, S., Vandemark, D., Viovy, N., Wiltshire, A., Zaehle, S., and Zeng, N.: Global Carbon Budget 2015, Earth Syst. Sci. Data, 7, 349396, doi:10.5194/essd-7-349-2015, 2015.

Li, X. and Liu, W.: Effect of preservation on the delta ${ }^{13} \mathrm{C}$ value of dissolved inorganic carbon in different types of water samples, Isot. Environ. Healt. S., 47, 379-389, doi:10.1080/10256016.2011.598934, 2011.

Liu, X., Byrne, R. H., Adornato, L., Yates, K. K., Kaltenbacher, E., Ding, X., and Yang, B.: In Situ Spectrophotometric Measurement of Dissolved Inorganic Carbon in Seawater, Environ. Sci. Technol., 47, 11106-11114, doi:10.1021/es4014807, 2013.

Maher, D. and Eyre, B. D.: Insights into estuarine benthic dissolved organic carbon (DOC) dynamics using $\delta^{13} \mathrm{C}$-DOC values, phospholipid fatty acids and dissolved organic nutrient fluxes, Geochim. Cosmochim. Ac., 75, 1889-1902, doi:10.1016/j.gca.2011.01.007, 2011.

Maher, D. T., Santos, I. R., Golsby-Smith, L., Gleeson, J., and Eyre, B. D.: Groundwater-derived dissolved inorganic and organic carbon exports from a mangrove tidal creek: The missing mangrove carbon sink?, Limnol. Oceanogr., 58, 475-488, doi:10.4319/lo.2013.58.2.0475, 2013a.

Maher, D. T., Santos, I. R., Leuven, J. R. F. W., Oakes, J. M., Erler, D. V., Carvalho, M. C., and Eyre, B. D.: Novel Use of Cavity Ring-down Spectroscopy to Investigate Aquatic Carbon Cycling from Microbial to Ecosystem Scales, Environ. Sci. Technol., 47, 12938-12945, doi:10.1021/es4027776, 2013b.

Maher, D. T., Santos, I. R., and Tait, D. R.: Mapping Methane and Carbon Dioxide Concentrations and $\delta^{13} \mathrm{C}$ Values in the Atmosphere of Two Australian Coal Seam Gas Fields, Water Air Soil Poll., 225, 2216, doi:10.1007/s11270-014-2216-2, 2014.

Maher, D. T., Cowley, K., Santos, I. R., Macklin, P., and Eyre, B. D.: Methane and carbon dioxide dynamics in a subtropical estuary over a diel cycle: Insights from automated in situ radioactive and stable isotope measurements, Mar. Chem., 168, 69-79, doi:10.1016/j.marchem.2014.10.017, 2015.
Martz, T. R., Daly, K. L., Byrne, R. H., Stillman, J. H., and Turk, D.: Technology for ocean acidification research: Needs and availability, Oceanography, 28, 40-47, doi:10.5670/oceanog.2015.30, 2015.

Midwood, A. J. and Millard, P.: Challenges in measuring the $\delta^{13} \mathrm{C}$ of the soil surface $\mathrm{CO}_{2}$ efflux, Rapid Commun. Mass Sp., 25, 232-242, doi:10.1002/rcm.4857, 2011.

Nara, H., Tanimoto, H., Tohjima, Y., Mukai, H., Nojiri, Y., Katsumata, K., and Rella, C. W.: Effect of air composition $\left(\mathrm{N}_{2}, \mathrm{O}_{2}\right.$, Ar, and $\left.\mathrm{H}_{2} \mathrm{O}\right)$ on $\mathrm{CO}_{2}$ and $\mathrm{CH}_{4}$ measurement by wavelength-scanned cavity ring-down spectroscopy: calibration and measurement strategy, Atmos. Meas. Tech., 5, 2689-2701, doi:10.5194/amt-5-2689-2012, 2012.

Newton, J., Feely, R., Jewett, E., Williamson, P., and Mathis, J.: Global Ocean Acidification Observing Network: Requirements and Governance Plan, 60 pp., http://www.goa-on.org/ docs/GOA-ON_plan_print.pdf, 2014.

O'Sullivan, D. W. and Millero, F. J.: Continual measurement of the total inorganic carbon in surface seawater, Mar. Chem., 60, 7583, doi:10.1016/S0304-4203(97)00079-0, 1998.

Pataki, D. E., Ehleringer, J. R., Flanagan, L. B., Yakir, D., Bowling, D. R., Still, C. J., Buchmann, N., Kaplan, J. O., and Berry, J. A.: The application and interpretation of Keeling plots in terrestrial carbon cycle research, Global Biogeochem. Cy., 17, 1022, doi:10.1029/2001GB001850, 2003.

Porowska, D.: Determination of the origin of dissolved inorganic carbon in groundwater around a reclaimed landfill in Otwock using stable carbon isotopes, Waste Manage., 39, 216-225, doi:10.1016/j.wasman.2015.01.044, 2015.

Sabine, C. L., Ducklow, H., and Hood, M.: International carbon coordination: Roger revelle's legacy in the intergovernmental oceanographic commission, Oceanography, 23, 48-61, 2010.

Smith, B. N. and Epstein, S.: Two Categories of ${ }^{13} \mathrm{C} /{ }^{12} \mathrm{C}$ Ratios for Higher Plants, Plant Physiol., 47, 380-384, 1971.

Taipale, S. J. and Sonninen, E.: The influence of preservation method and time on the $\delta^{13} \mathrm{C}$ value of dissolved inorganic carbon in water samples, Rapid Commun. Mass Sp., 23, 2507-2510, doi:10.1002/rcm.4072, 2009.

Van Geldern, R., Verma, M. P., Carvalho, M. C., Grassa, F., Delgado-Huertas, A., Monvoisin, G., and Barth, J. A. C.: Stable carbon isotope analysis of dissolved inorganic carbon (DIC) and dissolved organic carbon (DOC) in natural waters - Results from a worldwide proficiency test, Rapid Commun. Mass Sp. 27, 2099-2107, doi:10.1002/rcm.6665, 2013.

Vogel, F. R., Huang, L., Ernst, D., Giroux, L., Racki, S., and Worthy, D. E. J.: Evaluation of a cavity ring-down spectrometer for in situ observations of ${ }^{13} \mathrm{CO}_{2}$, Atmos. Meas. Tech., 6, 301-308, doi:10.5194/amt-6-301-2013, 2013.

Webb, J. R., Maher, D. T., and Santos, I. R.: Automated, in situ measurements of dissolved $\mathrm{CO}_{2}, \mathrm{CH}_{4}$, and $\delta^{13} \mathrm{C}$ values using cavity enhanced laser absorption spectrometry: Comparing response times of air-water equilibrators, Limnol. Oceanogr.-Meth., 14, 323-337, doi:10.1002/lom3.10092, 2016. 